www.jmscr.igmpublication.org

Impact Factor (SJIF): 6.379

Index Copernicus Value: 71.58

ISSN (e)-2347-176x ISSN (p) 2455-0450

crossref DOI: _https://dx.doi.org/10.18535/jmscr/v6i3.176

Journal Of Medical Science And Clinical Research

IGM Publication

An Official Publication of IGM Publication

\title{
Diagnostic Efficiency of Cell Block Method over Conventional Smear Method in the Cytology of Malignant Effusions- A Prospective Study
}

\author{
Authors \\ Dr Tanya S Ponnatt, Dr Deepthy Vijayaraghavan, Dr Lincy Joseph, \\ Dr C S Sakunthala Bhai \\ Jubilee Mission Medical College \& Research Institute, Thrissur, Kerala \\ Corresponding Author \\ Dr Deepthy Vijayaraghavan \\ Phone Number: 9447240310, Email: deepthy2001@gmail.com
}

\begin{abstract}
Background: Cytological examination of body fluids has increasingly gained acceptance in clinical medicine to such an extent that a positive diagnosis made is often considered definitive diagnosis. It is of utmost importance to identify primary site and type of malignancy. The aim of this study is to compare the diagnostic efficiency \& morphological features of cell block \& conventional smear method in malignant fluid samples. This study also evaluates the usefulness of immunohistochemistry on cell blocks in identifying the primary site of malignancy

Methods: Cell blocks \& conventional Smears from 30 malignant fluid samples were prepared. Morphological features (like cellularity, nuclear features, cytoplasmic features \& pattern) and final diagnosis were compared in both. Immunohistochemistry was performed on cell blocks to identify the primary site of malignancy. The results obtained by immunohistochemistry were compared to the final histopathological diagnosis of the primary malignancy.

Results \& Discussion: The morphological features were found to be superior in cell block method compared to conventional smear method. The diagnostic efficiency of cell block was $86.7 \%$ whereas that of conventional smear was only 80\%. Combined diagnostic efficiency of the two methods was $96.7 \%$. Immunohistochemistry done on cell blocks could identify the primary malignancy or atleast suggest two or three possible sites of primary in all 30 cases.

Conclusions: Cell block in conjunction with smears helps increase the accuracy of fluid diagnosis. The better morphological features and the use of immunohistochemistry to help identify primary site of malignancy gives a more definitive diagnosis by the cell block method.
\end{abstract}

Keywords: Cell block, Conventional smear, Immunohistochemistry.

\section{Introduction}

The cytological examination of serous fluids is of utmost importance in the diagnosis, staging and prognosis of malignant lesions ${ }^{(1)}$. The development of malignant pleural effusion is a common presentation of cancers like pulmonary, breast and gastric carcinoma ${ }^{(2)}$. If malignant cells are seen in the pleural, pericardial or ascitic fluid, it almost always points out to metastatic tumors. While screening the effusion cytology smears for malignancy, reactive mesothelial cells is a commonly encountered problem. The lower 
sensitivity is mainly attributable to bland morphological detail of cells, overcrowding or overlapping of cells, cell loss and changes due to different laboratory processing in the conventional smear method ${ }^{(3)}$.

The cell block method is one of the oldest methods for the evaluation of body fluids. It can be used as an adjunct to smears for establishing a more definitive cytopathological diagnosis. Its main advantage is increased cellularity, the preservation of tissue architecture, and obtaining multiple sections for special stains \& immunohistochemistry. Patterns of arrangement of cells are better appreciated in cell block ${ }^{(4)}$. There are several methods of the cell block preparation like fixed sediment method, plasma thrombin clot method, bacterial agar method, cell block from millipore filter method, etc. The most widely accepted method for cell block preparation uses $10 \%$ alcohol formalin as fixative, which is a very simple and inexpensive method. It does not require any special training or sophisticated instrument. Aspiration biopsy material (FNA), sputum, effusions, urine sediment, and material from the gastrointestinal tract, can also be subjected for cell block processing, as are all tissue fragments incidentally obtained during any other diagnostic cytologic procedure ${ }^{(5)}$.

\section{Methods}

All pleural fluid, pericardial and ascitic fluid samples received in the Department of Pathology, Jubilee Mission Medical College for the next one and a half years were subjected to cell block and conventional smear examination.

The samples were collected in clean test tubes or containers, half of which were used for conventional smear method and the other half for cell block method.

In the conventional smear technique, the fluid sample were centrifuged at $2500 \mathrm{rpm}$ for 15 mins. A minimum of 3 smears were prepared from the sediment. Two of the smears were immediately fixed in $80 \%$ isopropyl alcohol and stained with Papanicolaou and Haematoxylin-Eosin stain. The third slide was air dried and stained with Leishman stain.

For the cell block technique, the fluid was centrifuged for 15 minutes at $2500 \mathrm{rpm}$ after adding $10 \%$ alcohol formalin fixative. The supernatant was poured off. $10 \%$ alcohol formalin was again added to the sediment and left overnight. On the following day, the sediment was scooped out on to filter paper and this sediment was processed along with other routine histopathological specimens. Paraffin embedded sections of 4-6 micro meter thickness were prepared and stained with hematoxylin and eosin stain. The slides were examined under the microscope ${ }^{(1)}$.

The slides were studied in detail taking into account the available clinical data, various investigation reports $\&$ morphological details. The samples were categorised as benign, suspicious for malignancy or malignant. All the samples that are suspicious for malignancy or were malignant by either the cell block method or the conventional smear method and where there was a biopsy correlation were included in the study population. Cytomorphological features like cellularity, arrangement of cells, cytoplasmic and nuclear details were compared for the above two methods. Immunohistochemistry was performed on the cell blocks to identify the primary site of malignancy using markers that included CK 7, CK 20 if the cytomorphology is that of a carcinoma. Additional markers will be used wherever relevant. The results of the fluid cytological examination \& cell block immunohistochemistry were be compared with the final histopathological diagnosis of the primary tumor.

\section{Results}

A total of 30 fluid samples were observed. The age of the patients range from 33-89 years. 7 cases $(23.3 \%)$ were males and 23 cases $(76.7 \%)$ were females. Among the 30 cases, there were 16 ascitic fluid samples, 8 pleural fluid, 2 pericardial fluid and 4 peritoneal washings. 
Cellularity was found to be better in the cell block method in $14(46.7 \%)$ of the cases and by conventional smear analysis in $6(20 \%)$ of the cases. In $10(33.3 \%)$ of the cases, there was not much difference in the cellularity. Nuclear features were found to be better by the Cell Block method in $16 / 30$ cases $(53.3 \%)$ and Conventional Smear method in $5 / 30$ cases $(16.7 \%)$. There was no considerable difference between Cell Block and Conventional Smear method in 9/30 cases (30\%). In the present study with 30 malignant fluid samples, cytoplasmic features were found to be better in $15(50 \%)$ cases by the cell block

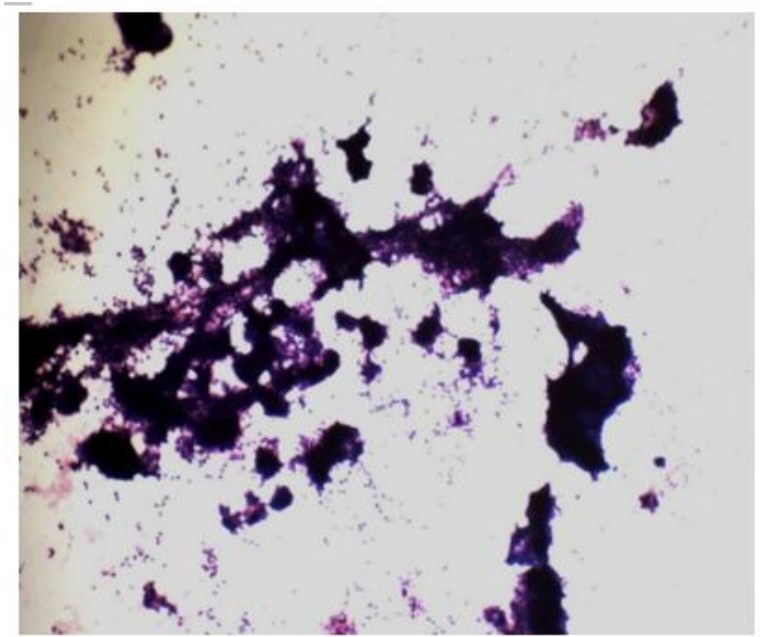

Picture 1a method and in $6(20 \%)$ cases by the conventional smear analysis. There was not much difference in the cytoplasmic features in $9(30 \%)$ of the cases. These findings are illustrated in Graph 1.The pattern of arrangement of cells (eg. glandular pattern) was better demonstrated by cell block method in $16 / 30(53.3 \%)$ and by Conventional Smear analysis in $7 / 30(23.3 \%)$ fluid samples. There was no considerable difference in the pattern of arrangement of cells in 4/30 (13.3\%) samples. 3/30 (10\%) samples showed no specific pattern of arrangement of cells.

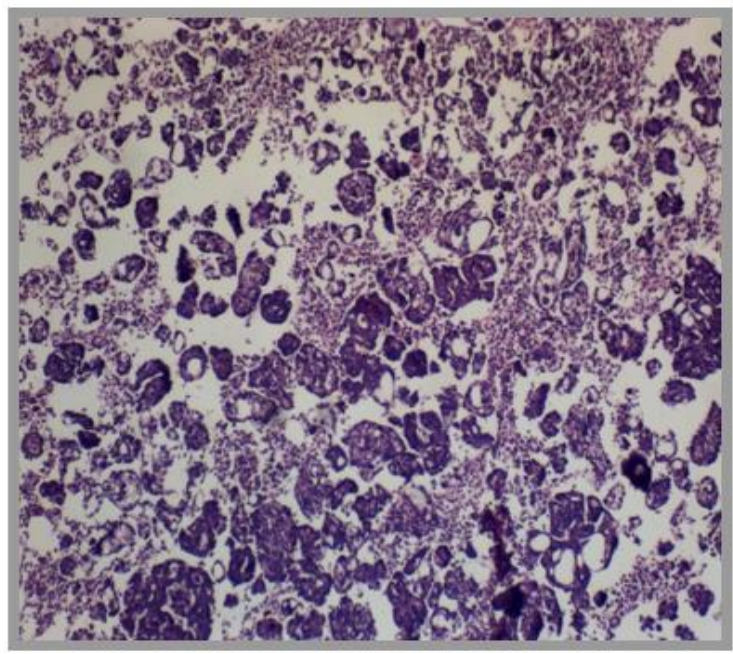

Picture 1b

Cellularity in conventional smear (1a) compared to cell block (1b), 10x, H\&E Ascitic fluid from a case of Serous Carcinoma Ovary

\section{Graph 1}

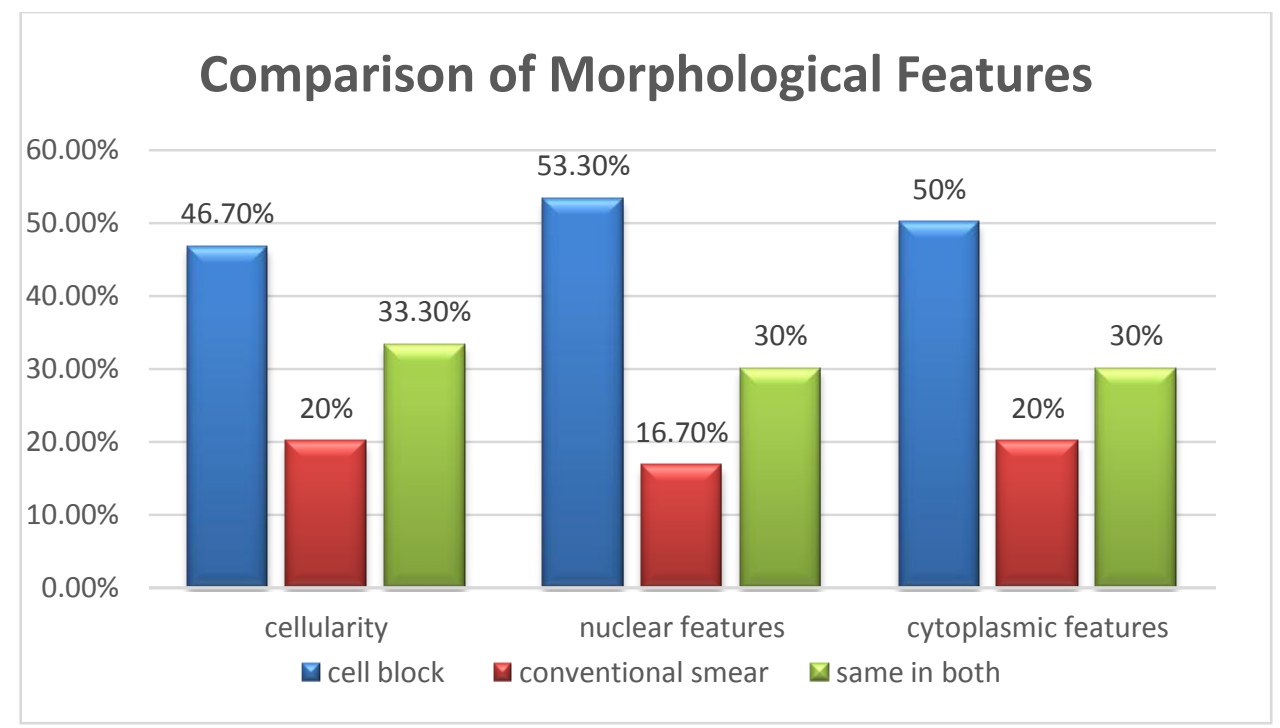




\section{JMSCR Vol||06||Issue||03||Page 1064-1073||March}

The final cytological diagnosis was positive for malignancy in $26 / 30(86.7 \%)$ cases by the cell block method and 24/30 (80\%) cases by conventional smear analysis. 4/30 (13.3\%) cases Graph 2 were suspicious for malignancy by cell block method whereas. 6/30 (20\%) cases were suspicious for malignancy by conventional smear analysis. (Graph 2)

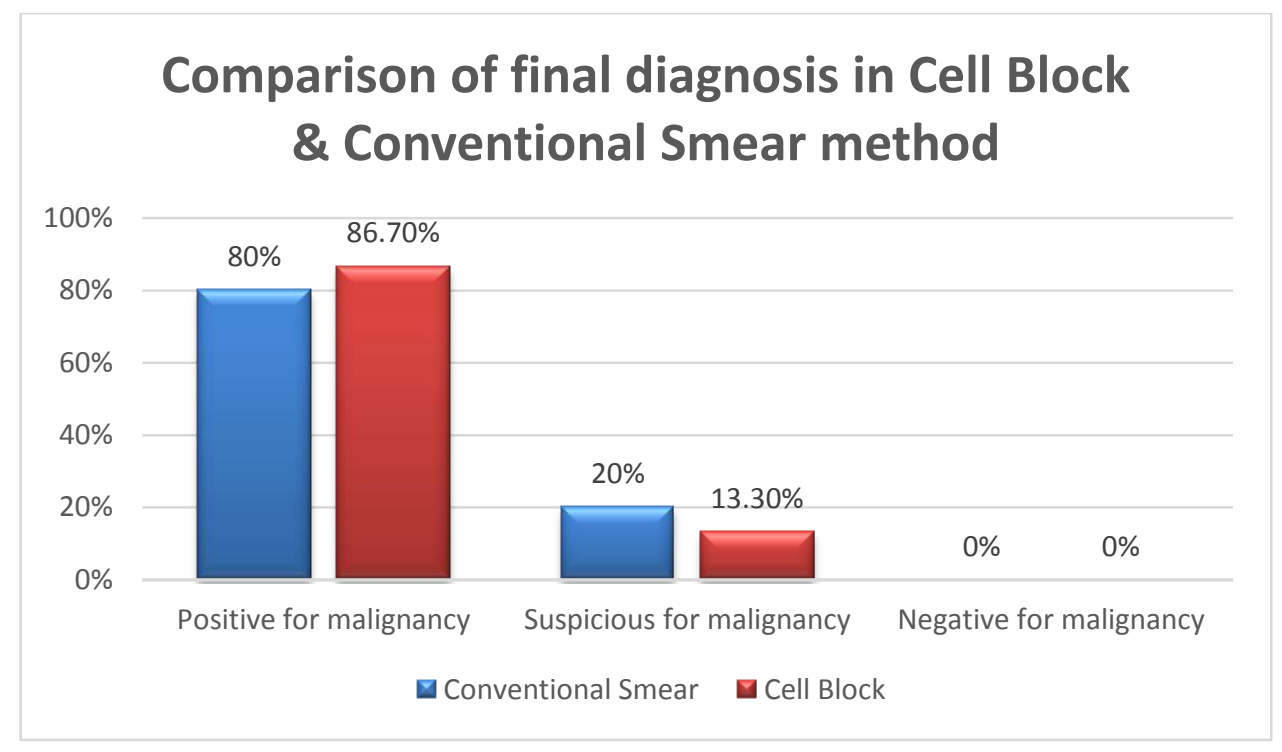

Only $1 / 30$ sample was suspicious for malignancy by both cell block and conventional smear method The diagnostic efficiency of cell block method was $26 / 30(86.7 \%)$ and of conventional smear method was 24/30 (80\%). (Graph 4) There was no statistically significant increase in diagnostic efficiency by cell block method over conventional smear analysis ( $p$ value by Fisher's Exact Test:1)

\section{Graph 3}

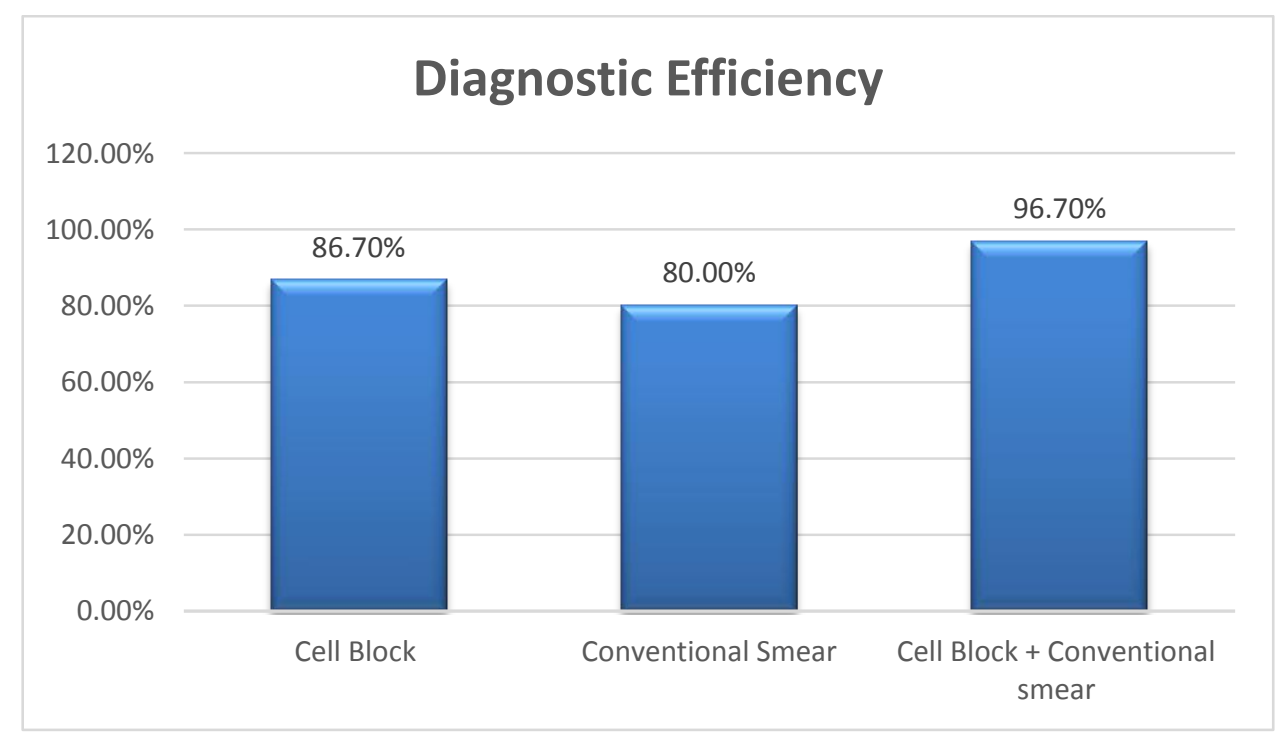

The sensitivity of cell block method was found to be $86.6 \%$ which was more than that of conventional smear method which was $80 \%$.
But on combining these two tests, the efficiency became 29/30 (96.7\%) which also showed no statistically significant increase in diagnostic efficiency when compared to cell block method ( $p$ value: 0.1 ) or conventional smear analysis ( $p$ value by Fischer's Exact Test: 0.2) alone. (Graph 3) 
Adenocarcinoma (8/30 cases), Carcinoma stomach (4/30 cases), Adenocarcinoma pancreas (3/30 cases), Mucinous carcinoma ovary (2/30 Graph 4 cases), Carcinoma breast (1/30 cases), Seromucinous carcinoma ovary (1/30 cases) and Carcinoma breast (1/30 cases) (Graph 4)

\section{Final diagnosis based on tissue biopsy}

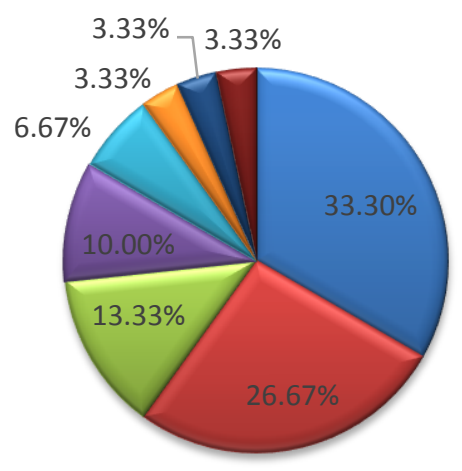

\begin{tabular}{|c|c|}
\hline D Serous carcinoma ovary & 口 Lung Adenocarcinoma \\
\hline 凶Carcinoma Stomach & 凹 Pancreatic carcinoma \\
\hline$\triangle$ Mucinous Carcinoma ovary & $\triangle$ Carcinoma breast \\
\hline
\end{tabular}

The most common primary malignancy in the female population was Serous Ovarian Carcinoma (10/23 cases) and in the male population, Adenocarcinoma lung (4/7 cases). The most common malignancy in the ascitic fluid sample was from Serous carcinoma ovary (8/16 cases). Among pleural fluid samples, $8 / 8$ cases were from Adenocarcinoma Lung.

Immunohistochemistry was done on the cell block of all the cases to find the primary malignancy. In
$19 / 30(63.33 \%)$ cases, it was possible to narrow down to a single primary malignancy. In 11/30 (36.67\%) cases, immunohistochemistry could help in suggesting $>1$ possible primary malignancies. There were no cases $(0 \%)$ where primary malignancy could not be identified. (Graph 5). In all 30 cases, the IHC diagnosis of primary malignancy correlated with the final histopathological diagnosis of the same.

\section{Graph 5}

\section{Use of Immunohistochemistry in identifying primary malignancy}

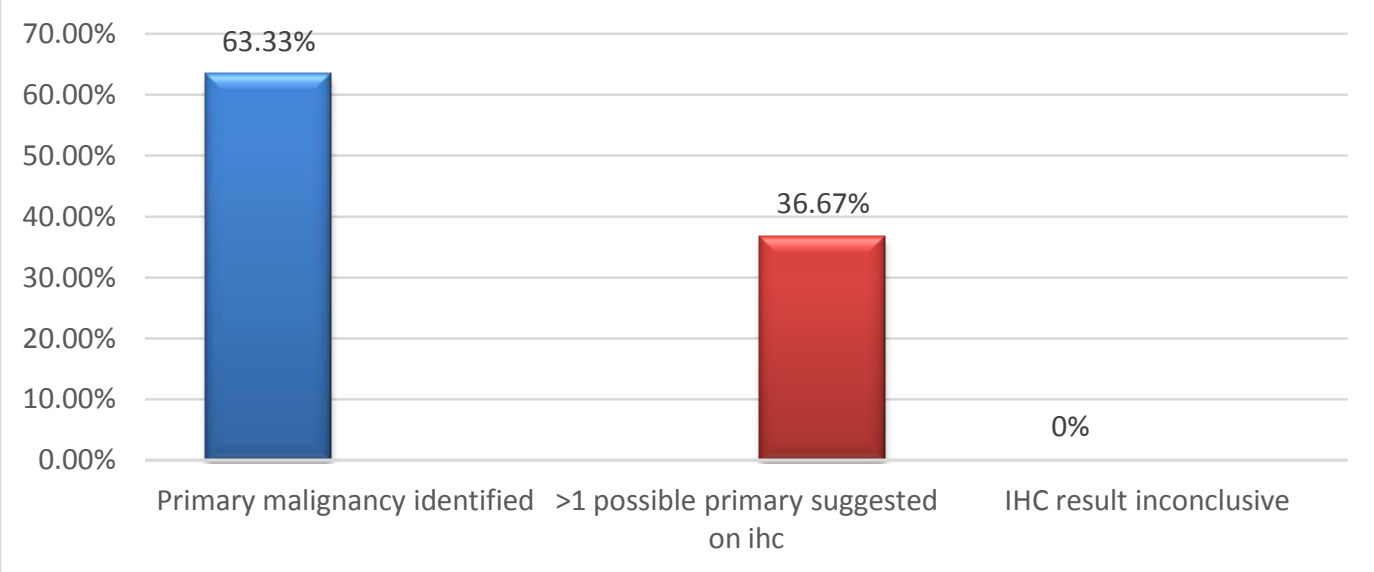




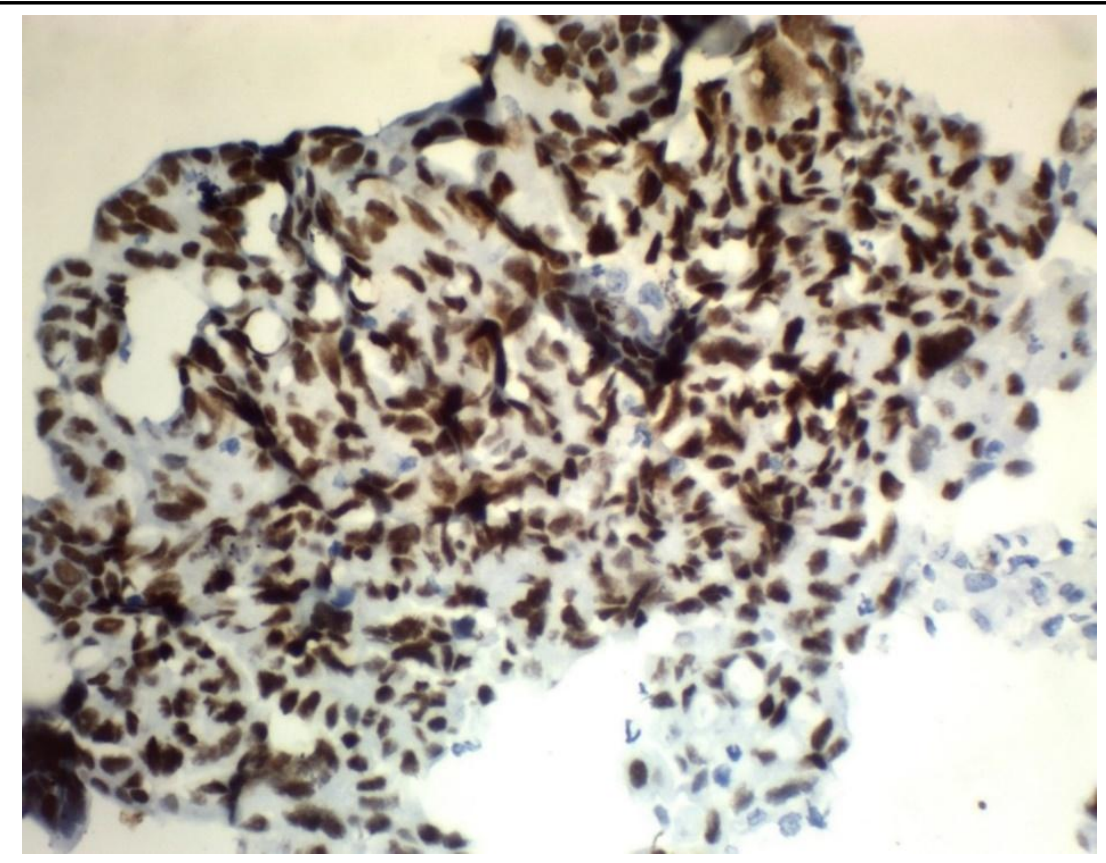

Picture 2: WT1 positive tumor cells from serous carcinoma ovary, 10X

\section{Discussion}

Cytologic examination has been used since a long time in the evaluation of the cellular components of body cavity fluids, including pleural, peritoneal, and pericardial effusions. Reactive mesothelial cells with atypical morphologic characteristics, however, sometimes are not easily distinguished from malignant cells by morphologic characteristics alone. The distinction between mesothelial cells and malignant cells in body cavity fluids remain a common challenging task. The purpose of this study was to analyse the effectiveness of cell block method over the conventional smear method. A total of 30 cases for which histopathological correlation or FNAC correlation from the primary tumor was available for comparison were included in this study.

In the present study, a total of 30 fluid samples were subjected to the conventional smear preparation and cell block techniques. Out of this 16 were ascitic fluids, 8 were pleural fluids, 2 were pericardial fluids and 4 cases were peritoneal washings. Peritoneal effusions $(66.6 \%)$, including ascitic fluid $(53.3 \%)$ and peritoneal washings $(13.3 \%)$ outnumbered pleural effusions $(26.7 \%)$ and pericardial effusions $(6.7 \%)$ in this study. Age of the patients ranged from 33-89 years. Mean age was 59.57 years and standard deviation 16.164 years. The mean age was found to be similar to most of the previous related studies. As regards gender, there was a very strong female preponderance $(76.7 \%)$ similar to the studies by Mohamed Fagere $^{(6)}$ and Shivakumarswamy ${ }^{(7)}$. Malignant effusions were observed to be mostly macroscopically hemorrhagic $(63.3 \%)$.

Cellularity was found to be better in most cases $(46.7 \%)$ by the cell block method as it concentrates cellular material, increases cell yield and forms a cell button. Architecture of cells was also found to be better in the cell block method. Features like cell balls, glandular and papillary pattern which are indicative of adenocarcinoma were better appreciated in the cell blocks. There was an ascitic fluid sample with cells in glandular pattern \& with numerous psammoma bodies which were more easily picked up on cell block. This was a strong clue to the primary tumor which was Serous Carcinoma Ovary. Nuclear \& cytoplasmic features were also better appreciated in the cell blocks. This could be due to the resemblance to tissue $\mathrm{H} \& \mathrm{E}$ staining.

In the present study diagnostic yield for malignancy was increased by the cell block method. The present study identified additional $6.67 \%$ (2 cases) malignancies by cell block method when compared to conventional smear 
method. Additional diagnostic yield of cell block was noted in various other studies. It was $6.33 \%$ in the study by Shubada et $\mathrm{al}^{(8)}$. In the study done by Bodele et al, additional $7 \%$ of malignant lesions were identified by cellblock method ${ }^{(9)}$. Khan et al in a study titled as usefulness of cellblock versus smears in malignant effusion cases reported that the recovery rate for malignant lesions by cellblock preparation is $20 \%$ greater than that obtained for specimen examined in smear only ${ }^{(10)}$. Richa Nathani et al reported 5\% increase in the diagnosis of malignancies ${ }^{(11)}$. According to the study by Shivakumarswamy, the increase in diagnostic yield by the cell block method was $15 \%^{(7)}$.

Table 1: Additional yield of malignancy in various studies by cell block

\begin{tabular}{|c|c|c|}
\hline SL No. & Study & \% \\
\hline 1 & Shubada et al & 6.33 \\
\hline 2 & Bodele et al & 7 \\
\hline 3 & RichaNathani et al & 5 \\
\hline 4 & Shivakumarswamy & 15 \\
\hline 5 & Khan et al & 20 \\
\hline 6 & Present study & 6.67 \\
\hline
\end{tabular}

By the conventional smear method, 24/30 (80\%) cases were positive for malignancy. This is higher than the study by Bhanvadia et al where 18/34 $(53 \%)$ of the malignant cases could be identified by CS alone ${ }^{(12)}$. Other studies by Chandler ${ }^{(13)}$ have shown $65 \%$ accuracy and by Ceelen ${ }^{(14)}$ proved $71 \%$ accuracy in the result by conventional smear method.

Table 2: Diagnostic accuracy of conventional smear method in various studies

\begin{tabular}{|l|c|c|}
\hline SL No. & Study & \% \\
\hline 1 & Bhanvadia et al & 53 \\
\hline 2 & Chandler & 65 \\
\hline 3 & Ceelen & 71 \\
\hline 4 & Present study & 80 \\
\hline
\end{tabular}

By the cell block method, 26/30 (86.7\%) cases were positive for malignancy. Ceelen has shown a diagnostic efficiency of $89 \%$ by the cell block method $^{(14)}$. The diagnostic accuracy reported in various other studies are as follows; Thapar et al $86 \%^{(15)}$, Bhanvadia et al $97 \%{ }^{(12)}$ and Zemansky AP $90 \%{ }^{(16)}$.

Table 3: Diagnostic accuracy of cell block method in various studies

\begin{tabular}{|l|c|c|}
\hline SL No. & Study & \% \\
\hline 1 & Ceelen & 89 \\
\hline 2 & Thapar et al & 86 \\
\hline 3 & Bhanvadia et al & 97 \\
\hline 4 & Zemansky AP & 90 \\
\hline 5 & Present study & 86.7 \\
\hline
\end{tabular}

By the cell block method, the number of cases that were suspicious for malignancy were 4/30 $(13.3 \%)$ cases and by conventional smear analysis, $6 / 30(20 \%)$ cases. But according to the study by Bhanvadia et al, it was $0 \%$ by cell block method and $11 \%$ by conventional smear analysis ${ }^{(12)}$.

Diagnostic efficiency of cell block and conventional smear together was found to be $96.7 \%$ which was more than that of conventional smear $(80 \%)$ or cell block $(86.7 \%)$ alone. Dekker A, Bupp PA in their study also reported similar findings ${ }^{(17)}$.

The sensitivity of cell block method was found to be $86.7 \%$. This is in accordance with the study by Nityananda where the sensitivity was found to be $89.4 \%^{(18)}$. Other studies by Wojcik and Selvaggihave shown a sensitivity of $84 \%{ }^{(19)}$. Leung and Bedardhave reported a sensitivity of 86 $\%$ by the cell block method ${ }^{(20)}$.

Table 4: Sensitivity of cell block method in various studies

\begin{tabular}{|c|c|c|}
\hline SL No. & Study & \% \\
\hline 1 & Nityananda & 89.4 \\
\hline 2 & Wojcik\&Selvaggi & 84 \\
\hline 3 & Leung \&Bedard & 86 \\
\hline 5 & Present study & 86.7 \\
\hline
\end{tabular}

In this study, the sensitivity of conventional smear analysis was found to be $80 \%$. Bhanvadia et al reported a sensitivity of $70 \%$ by conventional smear method ${ }^{(12)}$. Other studies by Oyafuso et al ${ }^{(21)} \&$ GG Nair et al ${ }^{(22)}$ have shown a much lower sensitivity of $44.5 \%$ and $32.3 \%$ respectively. 
Table 5: Sensitivity of conventional smear method in various studies

\begin{tabular}{|l|c|c|}
\hline SL No. & Study & \% \\
\hline 1 & Bhanvadia et al & 70 \\
\hline 2 & Oyafuso & 44.5 \\
\hline 3 & GG Nair & 32.3 \\
\hline 5 & Present study & 80 \\
\hline
\end{tabular}

The positive predictive value of cell block method was found to $86.7 \%$ \& that of conventional smear analysis $80 \%$. Both these values were higher than that obtained by G.G Nair which was $33.56 \%$ for cell block method \& $14.48 \%$ for conventional smear analysis ${ }^{(22)}$.

The most common primary malignancy in the fluid samples was Serous Carcinoma Ovary $(33.3 \% \%)$ in the present study; similar to the studies by Karki $\mathrm{S}$ et $\mathrm{al}^{(23)}$, Bjorn et $\mathrm{al}^{(24)}$ and Zachon et $\mathrm{al}^{(25)}$. Other malignancies included Lung Adenocarcinoma (26.67\%), Carcinoma Stomach (13.33\%), Carcinoma Pancreas (10\%), Mucinous Carcinoma Ovary (6.67\%), Carcinoma Breast (3.33\%), Seromucinous Carcinoma (3.33\%) and Carcinoma Rectum (3.33\%).The most common cause for malignant pleural effusion was Adenocarcinoma Lung and that of malignant ascites, Serous Ovarian Carcinoma. This is concordance with the studies by Ghosh et al $^{(26)} \&$ Bhanvadia et al ${ }^{(12)}$.

Immunohistochemistry was done on the cell block of all 30 cases to find the primary malignancy. In $19 / 30(63.33 \%)$ cases, it was possible to narrow down to a single primary malignancy. In $11 / 30$ (36.67\%) cases, immunohistochemistry could help in suggesting 2 or 3 possible primary malignancies. There were no cases $(0 \%)$ where primary malignancy could not be identified. The best results for identifying the primary malignancy was for metastatic Serous Carcinoma Ovary and Adenocarcinoma Lung. Pomjanski $\mathrm{N}$ et al in his study also reported similar results in identifying primary malignancies ${ }^{(27)}$.

\section{Conclusion}

Diagnostic efficiency of the cell block method is superior than that of conventional smear analysis.
When cell block \& conventional smear analysis were combined together, the diagnostic efficiency is more than that of either method done alone. Immunohistochemistry performed on cell blocks can help in identifying the primary site of origin in carcinoma of unknown primary.

\section{Acknowledgement}

I express my sincere thanks to my Professors Dr Deepthy Vijayaraghavan, Dr Lincy Joseph \& Dr CS Sakunthala Bhai for their patient guidance, helpful criticism and advices throughout this study.

\section{Bibliography}

1. Koksal.D, Demirag.F, Bayiz.H, Koyuncu. A, Mutluay.N, Berktas.B, etal., The Cell Block Method increases the diagnostic yield inexudative pleural effusions accompanying lung cancer, Turkish Journal of Pathology 2013;29 (3),165-170.

2. Udasimath.S, Arakeril.S.U, Karigowdar. M.H, Yelikar.B.R, The role of cell block method in the diagnosis of malignant ascetic fluid effusions, Journal of Clinical and Diagnostic Research 2012;6(7),12801283

3. Viral.M.B, Santwani.P.M and Vachhani. J.H, Ethiopian Journal of Health Science 2014; 24(2), 125-131

4. Thapar.M, Mishra.R.K, Sharma.A, Goyal.V, Goyal.V, Critical analysis of cell block vs smear examination in effusions, Journal of Cytology 2009; 26(2),60-64

5. Dekker.A, Bupp P.A, Cytology of serous effusions. An investigation into the usefulness of cell block vs smears. American Journal of Clinical Pathology 1978; 70(6), 855-860

6. Fagere MO. Diagnostic Utility of AgNORs Staining of Serous Effusion among Sudanese Patients. International Journal of Science and Technology. 2016 Jan;5(1):36-42 
7. Shivakumarswamy U, Arakeri SU, Karigowdar MH, Yelikar B R. Diagnostic utility of the cell block method versus the conventional smear study in pleural fluid cytology.JCytol 2012;29:11-15

8. Bansode Shubhada ,Kumbalkar , Nayak. Cell Block Technique in the Cytodiagnosis of Body Fluids. International Journal of Science and Research. 2015 July;4(7):8794

9. Bodele AK, Parate SN, Wdadekar AA, Bhohate SK, Munshi MM. 2003. Diagnostic Utility of Cell Block Preparation in Reporting of Fluid Cytology. Journal of Cytology 20:133-5

10. Khan N, Sherwani RK, Afroz N, Kapoor S .Cytodiagnosis of malignant effusion and determination of primary site. Journal of Cytology. 2005; 22(3):107-110

11. RichaNathani, Rakesh Singh Hazari, Yogesh G. Patle, Santosh Gupta. Comparative analysis of cavity effusions by cell block and smear examination. International journal of recent trends in science and technology.Aug 2014;12(1):69-72

12. Santwani PM, Vachhani JH. Analysis of Diagnostic Value of Cytological Smear Method Versus Cell Blocks Method in Body Fluid Cytology: Study of 150 Cases. Ethiopian journal of health sciences. 2014;24(2):125-30.

13. Foot NC. The identification of neoplastic cells in serous effusions. Am J Pathol. 1939;27:53-60.

14. Guenther H. Ceelen: The cytologic diagnosis of ascitic fluid. Acta Cytol. 1964; 8:175-185.

15. Thapar M, Mishra RK, Sharma A, Goyal V. A critical analysis of the cell block versus smear examination in effusions. $\mathbf{J}$ Cytol 2009;26:60-64

16. Zemansky AP. The examination of fluid for tumour cells. An analysis of 113 cases checked against subsequent examination of tissue. Am J M Sci. 1928;175:489504.

17. Dekker A, Bupp PA. Cytology of serous effusions. An investigation into the usefulness of cellblocks versus smears. Am J Clin Pathol 1978;70(6):855-860

18. Nithyananda A. Nathan, CFIAC, Eddie Narayan, BAppSci, Mary M. Smith, BS, and Murray J. Horn, MApp Sci. Cell Block Cytology, Improved Preparation and Its Efficacy in Diagnostic Cytology. Am J Clin Pathol 2000;114:599-606 6.

19. Wojcik EM, Selvaggi SM. Comparison of smears and cell blocks in the fine needle aspiration diagnosis of recurrent gynecologic malignancies. Acta cytologica. 1991;35(6):773-6.

20. Leung SW, Bedard YC. Methods in Pathology: Simple mini block technique for cytology. Mod Pathol. 1993;6:630-2.

21. Oyafuso MS, Longatto Filho A, Bortolan J, Rahal P, Bisi H, Lombardo V. Cytological diagnosis of serous effusions in a cancer hospital in Brazil. Pathologica. 1996; 88:128-31

22. Nair GG, Manjula AA. Comparative study of cell-blocks \& routine cytological smears of pleural \& peritoneal fluids in suspected cases of malignancy. Indian Journal of Pathology and Oncology. 2015 Apr;2(2):61-8.

23. Karki S, Jha A, Sayami G. The role of argyrophilic nucleolar organizer región (AgNOR) study in cytological evaluation of fluids, especially for detection of malignancy. Kathmandu University Medical Journal. 2012 Oct 2;10(1):34-9.

24. Bjorn R, Ben D, Hiep P Dong. Flow cytometricimmunophenotyping of serous effusions and peritoneal washing comparison with immunocytochemistry and morphological findings. J ClinPathol 2000;53:513-7.

25. Zachon K, Tzartza E, Skenteri A, Orologa A. Ascitic fluid, peritoneal washing and 
cul de sac aspiration cytology in women under the age of 40: a retrospective study. Cytopathology 2004;15:14-7.

26. Ghosh I, Dey SK, Das A, Bhattacharjee D, Gangopadhyay S. Cell block cytology in pleural effusion. Journal of the Indian Medical Association. 2012;110(6):390392. 396.

27. Pomjanski N, Juergen Grote H, Doganay P, Schmiemann V, Buckstegge B, Böcking A. Immunocytochemical identification of carcinomas of unknown primary in serous effusions. Diagnostic cytopathology. 2005 Nov 1;33 (5) : 309-15. 